NBER WORKING PAPER SERIES

\title{
THE WELFARE COST OF BUSINESS CYCLES REVISITED: FINITE LIVES AND CYCLICAL VARIATION IN IDIOSYNCRATIC RISK
}

\author{
Kjetil Storesletten \\ Chris I. Telmer \\ Amir Yaron \\ Working Paper 8040 \\ http://www.nber.org/papers/w8040
NATIONAL BUREAU OF ECONOMIC RESEARCH
1050 Massachusetts Avenue
Cambridge, MA 02138 \\ December 2000
}

For helpful discussions we thank Marianne Baxter, Michael Brandt, Chris Geczy, Joao Gomes, Per Krusell, José Victor Ríos-Rull, Tony Smith, Stan Zin and, especially, Rao Aiyagari who originally suggested using our framework to assess the welfare costs of business cycles. This work has benefited from the support of NSF grant SES-9987602 and the Rodney White Center at Wharton. The views expressed in this paper are those of the authors and not necessarily those of the National Bureau of Economic Research.

(C) 2000 by Kjetil Storesletten, Chris I. Telmer, and Amir Yaron. All rights reserved. Short sections of text, not to exceed two paragraphs, may be quoted without explicit permission provided that full credit, including (C) notice, is given to the source. 
The Welfare Cost of Business Cycles Revisited:

Finite Lives and Cyclical Variation in Idiosyncratic Risk

NBER Working Paper No. 8040

December 2000

JEL No. F21, D31, E32

\begin{abstract}
$\underline{\text { ABSTRACT }}$
This paper investigates the welfare costs of business cycles in a heterogeneous agent, overlapping generations economy which is distinguished by idiosyncratic labor market risk. Aggregate variation arises both in terms of aggregate productivity shocks and countercyclical variation in the volatility of idiosyncratic shocks. Based on both aggregate data and microeconomic data from the Panel Study on Income Dynamics, we find the welfare benefits of eliminating aggregate variation to be large - an order of magnitude larger than those originally documented by Lucas (1987). The key difference is countercyclical variation in idiosyncratic risk, which both amplifies the welfare cost of aggregate productivity shocks and imposes a cost of its own. The magnitude of these effects increases non-linearly in risk aversion. Our results support the increasingly popular notion that distributional effects are an important aspect of understanding the welfare cost of business cycles.
\end{abstract}

Kjetil Storesletten

Institute for Int'l Economic Studies

University of Stockholm

S-106 91 Stockholm

SWEDEN

and CEPR

storeslk@iies.su.se

Amir Yaron

The Wharton School

University of Pennsylvania

2256 Steinberg-Dietrich Hall

Philadelphia, PA 19104

and NBER

yarona@savage.wharton.upenn.edu
Chris I. Telmer

Graduate School of Industrial Administration Frew and Tech Streets

Carnegie-Mellon University

Pittsburgh, PA 15213

chirs.telmer@cmu.edu 


\section{Introduction}

The notion that an important macroeconomic policy objective should be the mitigation of business cycles is a familiar one, both in academic and non-academic circles. In his influential monograph, Lucas (1987) challenged this orthodoxy by demonstrating, in a representative agent environment, that the welfare gains associated with eliminating variation in aggregate consumption are miniscule. Subsequent work has challenged Lucas' finding on a number of grounds, ranging from statistical assumptions regarding aggregate consumption, to assumptions about preferences, to the basic assumptions underlying the representative agent paradigm. Our paper follows along this latter tack. The main idea is that there are important distributional effects associated with aggregate variation and that these distributional effects lie at the heart of why individuals care about business cycles. The primary effects we focus on are cyclicality in the cross-sectional variance of idiosyncratic risk - the idea that individual-specific shocks become more volatile during aggregate downturns - and how this interacts with life-cycle consumption and savings decisions. What we mean by a 'business cycle,' therefore, goes beyond aggregate productivity shocks to include shocks to the cross-sectional distribution.

We find large welfare gains from eliminating business cycles - approximately an order of magnitude larger than what Lucas (1987) found. About a half of the overall welfare gain is attributable to how much agents value the removal of countercyclical heteroskedasticity in the idiosyncratic shocks they face. The remainder is due to the removal of aggregate productivity shocks. The costs associated with these shocks are significantly amplified by the presence of the cyclical variation in idiosyncratic shocks and rise non-linearly with risk aversion.

The specifics of our analysis are as follows. We begin by providing evidence that the focal point of our study - persistent idiosyncratic risk in the labor market, distinguished by countercyclical heteroskedasticity — is a robust feature of U.S. data. Borrowing from previous work, we provide both qualitative evidence as well as quantitative estimates of a specific time series process. Next, we embed these estimates in an overlapping generations (OLG) model in which agents face both aggregate and idiosyncratic sources of uncertainty. The latter arises in the form of persistent shocks to individual labor market productivity. The model's financial market structure, in conjunction with the stochastic process for idiosyncratic shocks and the fact that lives are finite, limits the extent to which agents can collectively pool idiosyncratic risk. As a result, the cyclical component in each individual's earnings process - an increase in volatility during aggregate downturns - is manifested in their consumption process, thereby leading to potential welfare benefits associated with the elimination of business cycles.

The methodology with which we measure welfare effects, and the quantitative results we find, are as follows. Our welfare calculations explicitly incorporate the 
transition from a world with business cycles to a world without business cycles. Such calculations are important because they ensure that the welfare results are not driven by the new economy's lower steady state level of capital stock. Our baseline model is an economy with both aggregate productivity shocks as well cyclical variation in the variance of idiosyncratic shocks. To begin with we eliminate only the aggregate productivity shocks. The welfare effects of doing so are large, being equivalent to a $1.44 \%$ increase in an agent's consumption. Next, we eliminate the variation in the variance of the idiosyncratic shocks, reformulating the process so that it has the same unconditional variance as in our baseline economy. The welfare costs in this case are also large, especially in light of previous work. We find that an unborn agent is better off by $5.09 \%$ and that, on average, the population is better off by $1.03 \%$. Finally, we ask to what extent "general equilibrium effects" — changes in market clearing prices due to changes in aggregate savings - are the driving force. By conducting experiments in which prices are not allowed to change we conclude that the bulk of our results are not attributable to these general equilibrium effects.

Two channels are the key for the sizable welfare gains we find. First, idiosyncratic earnings shocks and aggregate productivity shocks interact in a way that amplifies the costs associated with cyclical variation in idiosyncratic risks. Experiencing larger idiosyncratic risks during downturns in aggregate productivity - a key feature of our economy - is effectively much more costly than experiencing the same cyclical variability in idiosyncratic risks absent any aggregate productivity shocks. Thus the welfare benefits of removing aggregate shocks are larger than the sum of the welfare gains of removing aggregate fluctuations in an economy without idiosyncratic shocks plus the welfare gains of removing the cyclical variation in idiosyncratic shocks in an economy without aggregate productivity shocks. This feature of our economy "when it rains it pours" - captures the notion that agents who already face larger idiosyncratic risks during downturns really dislike having things magnified by a decline in aggregate output.

The second channel is due to the stochastic properties of the regime shifting process for idiosyncratic shocks. Our estimates for the magnitude for the increase in idiosyncratic risk during downturns are quite large and imply an unconditional distribution of idiosyncratic shocks that is leptokurtic (i.e., the regime shifting nature of the conditional distribution leads to a fat-tailed unconditional distribution). Because agents in our economy dislike kurtosis, and because the elimination of business cycles leads to normally distributed idiosyncratic shocks, this represents an avenue for welfare gains. Finally, it is important to note that, in contrast to Lucas's welfare measure which rises linearly in agents' risk aversion, both of the channels described above depend in a highly non-linear fashion on risk aversion, thereby generating quite large welfare gains even for moderate levels of risk aversion.

Our study follows a long line of papers on the welfare costs of business cycles. Most closely related are studies which focus on the interaction between business cy- 
cles, heterogeneous agents and uninsurable labor market risk, including Atkeson and Phelan (1994), Beaudry and Pages (1999), İmrohoroğlu (1989), and Krusell and Smith (1999). What distinguishes us is an OLG framework and the way in which we model and calibrate the process which drives heterogeneity. We focus on earnings as opposed to unemployment, and calibrate our model using microeconomic data from the Panel Study on Income Dynamics (PSID). The latter leads to substantially more volatile and persistent idiosyncratic shocks with a greater dependence on aggregate variation. Finally, our approach is similar in spirit to İmrohoroğlu (1989), but departs from the approach of Atkeson and Phelan (1994) and Krusell and Smith (1999), who assume that the cyclical distribution of idiosyncratic risk is impervious to changes in the aggregate technological process. The dependence between aggregate and idiosyncratic shocks in our framework leads to the distinct result that the welfare gains we identify are due to the elimination of both of these shocks.

The paper continues as follows. In section 2 we present empirical evidence on idiosyncratic risks and how it varies over business cycles. Section 3 presents our model and section 4 describes our calibration strategy. Section 5 presents quantitative results and section 6 provides some concluding remarks.

\section{Evidence}

Our question is inherently one about how income and consumption variation across households is related to aggregate, time series variation. In order for this question to have empirical content, we require that the cross-sectional distribution of labor income exhibit the following three properties. First, there must be an interesting cross-sectional distribution to begin with. In our framework this translates to the requirement that individual-specific income must contain an idiosyncratic component which is of sufficient variability. Second, the innovations associated with this process must be quite persistent. Without persistence our theory turns out to closely resemble a theory in which heterogeneity is absent, thereby rendering our question moot. Finally, for the reasons outlined above, the volatility of these innovations must increase during aggregate downturns. In this section we summarize previous work which argues that these are robust features of U.S. data.

Our data correspond to the years 1969-1992 and are obtained from the Panel Study on Income Dynamics (PSID). We examine data at the household level and define annual labor market earnings to equal wages and salaries plus various transfer payments (e.g., unemployment insurance, workers compensation, transfers from non-household family members, and so on). Transfers are included so as to provide measures of idiosyncratic risk net of the risk sharing mechanisms which these payments implicitly

represent, mechanisms which are absent from our model. We construct a sequence of 22 overlapping panels each with a three year time horizon. For example, our ' 1975 panel' features three time series observations on each household, covering the years 
1975, 1976 and 1977. This feature of our dataset — its departure from the standard longitudinal approach of requiring that all households be represented in all years - is distinct and has a number of important advantages. It provides sufficient time series information and at the same time features a relatively large sample size, a limited degree of survivorship bias and, most importantly, a stable cross-sectional distribution of age across time. The latter is particularly important for our questions, which relate aggregate shocks to idiosyncratic shocks in a life cycle context (i.e., one cannot learn much about labor market shocks from a group of retirees). This comes at a cost, of course, which in our case is primarily related to measurement error and the loss of information associated with restricting ourselves to three time series observations. For more explicit details and more information on the pros and cons of our empirical methodology, we refer the reader to Storesletten, Telmer, and Yaron (1999).

The time series process we are interested in is as follows. Define $u_{t}^{h}$ as the idiosyncratic component of the earnings process of an $h$ year old household, at date $t$. We specify the process for $u$ as a mean zero ARMA process - a process with both a transitory and a persistent component — with heteroskedastic innovations in the persistent component:

$$
\begin{aligned}
u_{i t}^{h} & =z_{i t}^{h}+\varepsilon_{i t} \\
z_{i t}^{h} & =\rho z_{i, t-1}^{h-1}+\eta_{i t},
\end{aligned}
$$

where household age, $h$, is made explicit only when the conditional distribution of a variable depends upon it. We assume that $\varepsilon_{i t} \sim \operatorname{Niid}\left(0, \sigma_{\varepsilon}^{2}\right), \eta_{i t} \sim \operatorname{Niid}\left(0, \sigma_{\eta}^{2}\left(Y_{t}\right)\right)$ and,

$$
\begin{aligned}
\sigma_{\eta}^{2}\left(Y_{t}\right) & =\sigma_{H}^{2} \text { if aggregate expansion at date } t \\
& =\sigma_{L}^{2} \text { if aggregate contraction at date } t,
\end{aligned}
$$

where $Y_{t}$ denotes aggregate income. Our methodology will admit any definition of what constitutes an aggregate expansion and contraction. For the results we present, we will use National Income and Product Account (NIPA) data, and define an expansion (contraction) as a year in which growth in real U.S. GNP per capita is above (below) its average over our sample.

Before presenting estimates of the parameters of equation (1) an informal graphical analysis is helpful. Figure 1 reports cross-sectional moments by age and time based on our PSID panel. The top panel - which reports the age profile of the cross-sectional variance - is informative for the magnitude of the parameter $\rho$. The graph demonstrates that over the working years earnings dispersion increases, loosely speaking, linearly. Given the process in equation (1), linearly increasing cross-sectional variance is associated with the value $\rho=1$. In Storesletten, Telmer, and Yaron (2000) we examine this relationship in more detail including, among other things, 'fixed-effects' 
in equation (1) and information contained in the autocovariances of $u$. We argue that values for rho close to unity are a very robust implication of our PSID data.

The bottom panel of Figure 1 pools our data across ages instead of time and, at a very informal level, suggests that countercyclical heteroskedasticity is a striking feature of the data. The correlation of the detrended mean and the standard deviation is -0.74 . The obvious weakness here is inference based on a very limited number of business cycles, with at most five occurring between 1969 and 1992. The econometric methodology to which we turn next attempts to overcome this by exploiting the interaction between age, time and cross-sectional variance, and the fact that we can condition on the macroeconomic history of the U.S. over a much longer time span.

\section{$2.1 \quad$ Estimation}

Figure 1 suggests that what we are after — evidence that idiosyncratic shocks are both persistent and countercyclically heteroskedastic - may be consistent with data from the PSID. We now turn to a more formal econometric interpretation of the data, which is a summary of results in Storesletten, Telmer, and Yaron (1999).

The essence of our methodology is that we make assumptions about initial conditions and interpret the process in equation (1) as being finite. This allows us to exploit the fact that we can associate an age, $h$, with each observation in our panel and, conditional on macroeconomic data from the National Income and Product Accounts (NIPA), estimate the parameters conditional on an agent-specific 'macroeconomic history.' A simple example helps to illustrate this point.

Ignoring the transitory shocks, $\varepsilon_{i t}$, suppose that there were only three generations: young, middle aged and old. Suppose also that the economy is in an expansion at the current time, but was in a recession during the previous two years. Finally, suppose that we only observe data dated at the current time, period $t$. The population crosssectional variances of the idiosyncratic processes, $u$, for each generation are,

$$
\begin{aligned}
\text { young : } E\left(u_{i t}^{1}\right)^{2} & =\sigma_{H}^{2} \\
\text { middle aged : } E\left(u_{i t}^{2}\right)^{2} & =\sigma_{H}^{2}+\rho^{2} \sigma_{L}^{2} \\
\text { old : } E\left(u_{i t}^{3}\right)^{2} & =\sigma_{H}^{2}+\rho^{2} \sigma_{L}^{2}+\rho^{4} \sigma_{L}^{2}
\end{aligned}
$$

Thus, given sufficiently many observations on $u$ for each generation, we can identify all three parameters without any time series observations on individual agents. The key piece of information we are exploiting is how the cross-sectional variance at date $t$ varies across age cohorts and how this interacts with what is essentially a cohort-specific macroeconomic history which is known at date $t$. Note also that our methodology is perfectly well defined for any values of $\rho$, including those greater than unity. That is, we do not suffer from the litany of issues which arise in the context 
of inference with potentially non-stationary time series processes. This comes at a cost, of course, in the form of assumptions regarding initial conditions. In Storesletten, Telmer, and Yaron (1999) and Storesletten, Telmer, and Yaron (2000) we argue that our results are robust to a number of variations along these lines, including first differencing, quasi differencing and the incorporation of 'fixed effects.'

In Exhibit 1 we reproduce GMM-based estimates from Storesletten, Telmer, and Yaron (1999) which are based on a generalization of this methodology, applied to our 1969-1992 panel. The analog of the above example — which exploits 3 years of macroeconomic information using only 1 year of microeconomic information - is that we incorporate data going back to 1910 in spite of having PSID data which only begins in 1969.

\section{Exhibit 1: Idiosyncratic Risk: Parameter Estimates}

\begin{tabular}{lcccc} 
& $\rho$ & $\sigma_{H}^{2}$ & $\sigma_{L}^{2}$ & $\sigma_{\varepsilon}^{2}$ \\
\hline Estimate & 0.916 & 0.037 & 0.181 & 0.025 \\
Standard Error & 0.009 & 0.007 & 0.033 & 0.007 \\
& & & & \\
\hline
\end{tabular}

Our estimates confirm what is suggested by Figure 1. Idiosyncratic shocks appear to be quite persistent, with an estimated autocorrelation coefficient of 0.92 . The evidence in favor of countercyclical heteroskedasticity is also striking. Our estimates imply that the conditional standard deviation of the persistent shocks increases by $126 \%$ from expansion to contraction.

There are a number of reference points which are suggestive of the robustness of these findings. In relation to persistence and the relative magnitude of the persistent and transitory shocks, papers by Abowd and Card (1989), Hubbard, Skinner, and Zeldes (1994) and MaCurdy (1982) find results which are quite similar to ours. In addition, in Storesletten, Telmer, and Yaron (2000) we estimate $\rho$ using a variety of alternative methods, including an examination of the implications for the crosssectional distribution of consumption, and find convincing evidence in support of values of $\rho$ between 0.95 and unity. In relation to the countercyclical heteroskedasticity, comparable studies are more difficult to find. Heaton and Lucas (1996) find evidence of much smaller effects than we do but, as we argue in Storesletten, Telmer, and Yaron (1999), this is to some extent predictable given differences in statistical methodology and data. One corroborating piece of evidence which we find convincing involves how changes in the conditional variance manifest themselves in changes in the unconditional cross-sectional variance. In Storesletten, Telmer, and Yaron (1999) 
we show that the implications of Exhibit 1 - relatively large cyclical changes in the conditional variance - are not necessarily inconsistent with the relatively modest changes in the cross-sectional variance documented in Figure 1. That is, given the aggregate dynamics and the demographic structure of our economy, the variance in the variance which we observe in Figure 1 implies, to some extent, the striking results presented in Exhibit 1.

To make this last point more concrete, it is instructive to consider the above three-generation example. Given generations of equal size, and given the process for aggregate dynamics which we employ below, the estimates in Exhibit 1 imply a (time series) standard deviation in the percentage changes in the conditional standard deviation of the cross-sectional distribution of 52 percent. The volatility in the percentage changes in the associated unconditional cross-sectional standard deviation is only 27 percent. Moreover, this effect will be strengthened by additional generations because the older a cohort is, the less the cross-sectional variance associated with that cohort will vary over time (i.e., with age, there is more 'averaging' within the distribution). The three-generation example, therefore, understates what is relevant for our data and our model, where there are 43 working-age generations.

\section{Theory}

We now embed the evidence of the previous section into a stationary overlapping generations (OLG) model. The motivation for a life cycle framework arises from previous work where we've argued that finite lives and a life-cycle pattern in idiosyncratic risk are important for understanding the mapping between income and consumption. The main idea is that the infinite horizon abstraction affords theoretical agents far greater ability to use financial markets to self-insure against idiosyncratic risk than actual agents seem to enjoy. Given this, a life cycle framework seems important for our current question, which presumes that idiosyncratic risk is an important aspect of consumption outcomes.

Our model is essentially a one-asset version of the framework developed in Storesletten, Telmer, and Yaron (1999), which is itself a variant of Ríos-Rull's (1994) model, designed to incorporate idiosyncratic risk. Agents are indexed by their age, $h$, where $h \in \mathcal{H}=\{1,2, \ldots, H\}$. Each of the $H$ age cohorts consists of a large number of atomistic agents who face uncertain lifetimes with maximum length of $H$ years. Each year a new cohort of agents are born and some positive fraction of each existing cohort dies. We use $\phi_{h}$ to denote the unconditional probability of surviving up to age $h$, with $\phi_{1}=1$, and use $\xi_{h}=\phi_{h} / \phi_{h-1}, h=2,3, \ldots, H$, to denote the probability of surviving up to age $h$, conditional on being alive at age $h-1$. The fraction of the total population attributable to each age cohort is fixed over time at $\varphi_{h}$ and the population grows at rate $\vartheta$. 
Each individual agent is characterized by a preference ordering over consumption distributions, an endowment process, and an asset market position. Preferences for an unborn agent are represented by,

$$
E \sum_{h=1}^{H} \beta^{h} \phi_{h} u\left(c_{h}\right),
$$

where $\beta$ denotes the utility discount factor, $c_{h}$ denotes the consumption of an $h$ year old agent, $u$ is the standard twice differentiable, strictly concave utility function and the expectation is assumed to be conditional on the state of the economy prior to birth.

Agents begin working at age 22 (or $h=1$ ) and, conditional on surviving, retire at age 65 (or $h=43$ ). After retirement they must finance consumption entirely from an existing stock of assets. Prior to retirement an agent of age $h$ receives an annual endowment, $n_{h}$, of an age-specific amount of labor hours (or, equivalently, productive efficiency units) which they supply inelastically to an aggregate production technology. Individual labor income is then determined as the product of hours worked and the market clearing wage rate.

We adopt the following process for the logarithm of hours worked,

$$
\log n_{h}=\kappa_{h}+z_{h}
$$

where

$$
z_{h}=\rho z_{h-1}+\eta_{h}, \eta_{h} \sim \mathrm{N}\left(\sigma_{\eta}^{2}(Z) / 2, \sigma_{\eta}^{2}(Z)\right)
$$

$Z$ is an aggregate productivity shock and $\kappa_{h}$ is a parameter used to match the cross sectional distribution of mean age-earnings profile. Idiosyncratic shocks, therefore, are comprised of both a transitory and a persistent component, following the time series model in section 2. Countercyclical heteroskedasticity arises in the form of time variation in the variance of the innovations to the persistent process. More specifically,

$$
\begin{aligned}
& \sigma_{\eta}^{2}(Z)=\sigma_{H}^{2} \text { if } Z \geq E(Z) \\
& \sigma_{\eta}^{2}(Z)=\sigma_{L}^{2} \text { if } Z<E(Z) .
\end{aligned}
$$

The notion of countercyclical heteroskedasticity is simply the condition that $\sigma_{H}<\sigma_{L}$.

Output in this world is produced by an aggregate technology to which individuals rent their labor services and capital. The production function takes the form,

$$
Y=Z f(K, N)
$$


where $K$ and $N$ represent per capita capital and labor, respectively, $Y$ represents per capita output, and $Z$ is a technology shock restricted to lie in a finite set $\mathcal{Z}$. Given aggregate consumption, $C$, and the rate of depreciation on aggregate capital, $\delta$, the law of motion for aggregate capital can be written,

$$
K^{\prime}=Y-C+(1-\delta) K
$$

The financial market structure allows agents to trade in only one asset, shares of ownership in the risky aggregate technology. Each agent's choice problem is onedimensional: given knowledge of their idiosyncratic status, they simply choose an amount of assets to accumulate, which we label $a_{h}$. Asset holdings are restricted to lie in a set $\mathcal{A}$.

The state of the economy can now be represented as a pair $(\mu, Z)$, where $\mu$ is a measure defined over an appropriate family of subsets of $S=(\mathcal{H} \times \tilde{\mathcal{Z}} \times \mathcal{A})$, where $\tilde{\mathcal{Z}}$ is the product space containing all possible idiosyncratic shocks. In words, $\mu$ is simply a distribution of agents across ages, idiosyncratic shocks, and capital holdings (wealth). The aspect of $\mu$ which is somewhat non-standard is that, because of the aggregate uncertainty in our economy, it must evolve stochastically over time (i.e., $\mu$ belongs to some family of distributions over which there is defined yet another probability measure). We therefore use $G$ to denote the law of motion of $\mu$, the cross sectional distribution of the economy,

$$
\mu^{\prime}=G(\mu, Z)
$$

This characterization of the state of the economy implies that prices for the risky rate of return on capital and wages can be expressed as $R(\mu, Z)$ and $W(\mu, Z)$ respectively. The timing convention we use is that consumption-saving decision decision are made at the end of the period and market returns are paid the following period at the realized capital rental rate. Thus, the decisions of an agent of age $h$ are constrained by

$$
\begin{aligned}
c_{h}+a_{h+1}^{\prime} \xi_{h+1} & \leq a_{h} R(\mu, Z)+n_{h} W(\mu, Z) \\
a_{h+1}^{\prime} & \geq \underline{a} \text { and } a_{H+1} \geq 0,
\end{aligned}
$$

where $a_{h}$ denotes beginning of period asset (or capital) holdings and $a_{h+1}^{\prime}$ denotes end of period asset holdings. The term $\xi_{h+1}$ - the conditional probability of surviving to age $h+1$ given that one survives to age $h$ - is a convenient way to represent perfect annuity markets, something we incorporate so as to focus on labor market risk only. The idea is simply that, because one may not survive to capture the benefit of saving, the sacrifice in terms of current consumption is reduced in a manner which is actuarially fair. 
Denoting the value function of an agent of age $h$ as $V_{h}$, an agent's choice problem can be represented as,

$$
V_{h}\left(z_{h}, a_{h}, Z, \mu\right)=\max _{a_{h+1}^{\prime}}\left\{u\left(c_{h}\right)+\beta \frac{\phi_{h+1}}{\phi_{h}} E\left[V_{h+1}^{\prime}\left(z_{h+1}^{\prime}, a_{h+1}^{\prime}, Z^{\prime}, G(\mu, Z)\right) \mid z_{h}, Z\right]\right\}
$$

subject to equations (7).

An equilibrium can now be represented as a collection of stationary price functions, $R(\mu, Z)$ and $W(\mu, Z)$, a set of cohort specific value functions and decision rules, $\left\{V_{h}, a_{h+1}^{\prime}\right\}_{h=1}^{H}$, and a law of motion for $\mu, \mu^{\prime}=G(\mu, Z)$, such that the firm's profit maximization problem is satisfied,

$$
\begin{aligned}
R(\mu, Z) & =Z f_{1}(K, N)-\delta+1 \\
W(\mu, Z) & =Z f_{2}(K, N)
\end{aligned}
$$

aggregate quantities result from individual decisions,

$$
\begin{aligned}
K & =\int_{S} a d \mu \\
N & =\int_{S} n d \mu,
\end{aligned}
$$

agents' optimization problems are satisfied given the law of motion for $(Z, \mu)$ (so that $\left\{V_{h}, a_{h+1}^{\prime}\right\}_{h=1}^{H}$ satisfy problem (8)), and the law of motion, $G$, is consistent with individual behavior.

\section{Calibration}

We interpret one period in our model as corresponding to one year of calendar time. The aggregate production technology is Cobb-Douglas:

$$
Y=Z K^{\theta} N^{1-\theta}
$$

We set $\theta$ equal to 0.4 (which corresponds to capital's share of national income being $40 \%$, cf. Cooley and Prescott (1995)) and allow for a 7.8\% annual depreciation rate on the aggregate capital stock. The average growth rate in GNP per capita is chosen to be $1.5 \%$ per year. The technology shocks, $Z$, follow a first-order Markov chain with parameter values chosen so that theoretical aggregate consumption matches the volatility and autocorrelation of aggregate U.S. consumption. The end-result is a 
two-state Markov chain for the aggregate shock with $Z \in\{-0.045,0.045\}$ and a probability of remaining in the current state of $2 / 3$. The latter implies an expected duration of a business cycle of 6 year. ${ }^{1}$

Turning to the characteristics of individual agents, preferences are identical (up to age-dependent mortality risk) and are described by equation (2). We parameterize the period utility function with the standard isoelastic specification,

$$
u(c)=\frac{c^{1-\gamma}-1}{1-\gamma}
$$

In our benchmark economy we set the risk aversion parameter, $\gamma$, to 4 and the utility discount factor, $\beta$, to 0.95 . The latter is chosen to generate an aggregate capital to output ratio of 2.9, which is within the range of standard estimates based on U.S. data (cf. Cooley and Prescott (1995)). The choice of $\gamma$ is motivated by Storesletten, Telmer, and Yaron (1999) who find that with $\gamma=4$ this type of an economy generates a sizable market price of risk (the Sharpe ratio). ${ }^{2}$ The market price of risk is important for evaluating the cost of business cycles. It is well known that the welfare costs of eliminating business cycles can be sensitive to whether an economy is calibrated to match 'real quantities' or 'asset pricing moments'. Otrok (1999) demonstrates this point for the case of habit formation. Alvarez and Jermann (1999) also exploit the link between business cycle costs and asset prices. The fact that our framework is, for the most part, consistent along both the asset pricing and business cycle dimensions is an important feature governing our choice of $\gamma$ for the benchmark economy.

The demographic structure of our economy is calibrated to correspond to several simple properties of the U.S. work force. Agents are born at age 22, retire at age 65 and are dead by age 80 . Retirement is defined as having one's labor income drop to zero and having to finance consumption from an existing stock of assets. Mortality rates are chosen to match those of U.S. females in 1991 and population growth is set to $1.0 \%$.

The process for idiosyncratic labor supply, equation (3), is implemented as a discrete approximation to the autoregressive time series model and is parameterized using our point estimates from Exhibit 1. The age dependent intercept terms, $\kappa_{h}$, are chosen so that, on average, our theoretical age-earnings profile matches that of the PSID. The persistent process, a regime-shifting autoregression for $z_{h}$ with $\sigma_{H}=0.425$, $\sigma_{L}=0.192$ and $\rho=0.916$, is approximated with a 19 -state Markov chain where the conditional heteroskedasticity is generated by variation in the transition probabilities, as opposed to the potential realizations of $z_{h}$. Further details are provided in

\footnotetext{
${ }^{1}$ Using the HP filter to detrend the data results in lower volatility and a model implied autocorrelation for consumption somewhat lower than the data. Our choice of deterending, however, seems to be the natural one given the simple two-state process for aggregate productivity.

${ }^{2}$ Specifically, in Storesletten, Telmer, and Yaron (1999) we find that with $\rho=1$ for individual earnings shocks and risk aversion set at $\gamma=4$, this economy replicates the observed market price of risk. Our choice of $\gamma$ is therefore on the conservative side.
} 
Storesletten, Telmer, and Yaron (1999). Finally, in our baseline economy we disallow short-selling of the risky technology (i.e. there is no borrowing) - thereby setting $\underline{a}=0$.

To compute equilibrium we use methods developed in Storesletten, Telmer, and Yaron (1999), which are finite-lived extensions of work by Castañeda, Díaz-Giménez, and Ríos-Rull (1998), den Haan (1994) and, in particular, Krusell and Smith (1998). Specifically, we approximate $\mu$, the distribution of capital across agents and age, with a finite number of moments and characterize the transition function $G(\mu, Z)$ corresponding to these moments. Given such a parameterization, agents decisions rules are derived from a finite dynamic programming problem. Using the decision rules we simulate the economy and derive an empirically determined distribution of agent-specific capital which can then be compared to the conjectured functional form for that distribution. An equilibrium is reached when the empirical process coincides with the parameterized process. We verify that in such an equilibrium agent's perceptions about $\mu$ and $G(\mu, Z)$ are very precise in the sense that Euler equation errors are very small.

We derive the stochastic stationary equilibrium for our benchmark economy and for each of the alternative economies we study. In computing the welfare gains of moving from our benchmark economy to one of the alternative economies, we solve for an equilibrium transition path. Having characterized the stochastic stationary equilibrium in each economy, we conjecture the matrices characterizing the cross-sectional distribution of capital and age $G(\mu, Z)$ during the transition and a time period by which the economy settles into the alternative economy's stochastic stationary equilibrium. These parameters are iterated upon until the equilibrium transition path is attained. Further details on the computations are available in Storesletten, Telmer, and Yaron (1999).

\section{Quantitative Results}

We start by describing the basic features of our baseline economy. We then describe how we compute welfare gains: "how much will individuals be willing to pay in order to move to an alternative economy?" Finally, we describe our welfare results as well as various experiments designed to isolate some of the economics underlying our results.

Our baseline economy is broadly consistent with several key features of the aggregate U.S. economy. Consumption is roughly $70 \%$ of the magnitude of output (which equals $50 \%$ for the private sector plus $20 \%$ for government sector which is not explicitly modeled). Table 1 demonstrates that our parameterization for technological shocks generates realistic stochastic behavior for various (endogenous) aggregate quantities. The variability in theoretical aggregate consumption and output is approximately the same as in the data. The autocorrelation of consumption matches 
the high autocorrelation found in the data. For output the model generates slightly smaller autocorrelation than that of output in the data. The lower autocorrelation in output, however, is a necessary implication of our two-state aggregate shock process averaging one 'cycle' every 6 years. In other words, given our simple process for aggregate variation, we can match either autocorrelation or some notion of 'cyclicality,' but not both. We choose the latter, largely because of the methodology used in the last section to measure countercyclical, cross sectional variation.

Our baseline economy is also consistent with several key moments of individual earnings and consumption. There are two sources for potential discrepancy between the calibrated theoretical income process, equation (3), and the PSID-based estimates from Exhibit 1. The first is the error induced by approximating an infinite-state autoregression with a finite-state Markov chain. The second is that we calibrate the process for hours worked to data on income received, where in the model labor income is an endogenous process - the product of the exogenous supply of hours worked and the endogenously determined wage rate. We find, however, that the combined effects of these sources of discrepancy are of negligible importance for the moments we focus on. Specifically, the mean, standard deviation and autocorrelation are very similar when comparing population moments from our model with sample analogs. We find that if we use our theoretical economy to generate an arbitrary long sequence of 3 year panel data sets (which correspond to our PSID sampling method), our GMM estimator (section 2.2) yields estimates which closely match those from Table 1; our simulated point estimates are 0.902, 0.029,0.172, and 0.028 for $\rho, \sigma_{H}^{2}, \sigma_{L}^{2}$, and $\sigma_{\epsilon}^{2}$, respectively. The overall implication is that the population moments for our model's labor income process closely match the sample moments underlying the estimates presented in Exhibit 1.

Our benchmark model is also consistent with several stylized facts on the crosssectional distribution on consumption. The annual cross-sectional variance of consumption growth in our model is 0.029 , which is close to what is observed in the CEX (e.g., Souleles (1999) finds the cross-sectional variance of consumption growth to have a mean of .023). The changes in this quantity do not fluctuate very much. The mean and variance are 0.0001 and 0.0007 respectively, both on the order of what Brav, Constantinides, and Geczy (2000) find in calibrating their economy. Moreover, a key channel by which these authors calibrate their economy is the time series regression of returns onto the variance of idiosyncratic risk in consumption growth. The corresponding regression result in our model is -0.157 , which is consistent with the parameter range they find in their analysis. Finally, in Storesletten, Telmer, and Yaron (2000) we remove business cycles from our analysis by explicitly controlling for cohort effects. We show that a model without business cycles, but otherwise with essentially the same features as those here, accounts for the empirical rise in consumption inequality across age. Hence, in spite of endowing our economy with substantial income shocks, the resulting distribution of consumption is quite consistent with the limited amount of evidence. 


\subsection{Welfare Comparisons Across Alternative Economies}

We denote the value function for an $h$-year-old agent living in economy $A$ as $V_{h}^{A}(\cdot)$. Similarly, $V_{h}^{B}(\cdot)$ denotes this agent's value function, should they live in an economy with an alternative stochastic process for income shocks, say economy $B$. The welfare gain associated with moving from economy $A$ to economy $B$ is measured as the proportional compensation required to increase consumption permanently in economy $A$, in a way that will make the agent indifferent between the two economies.

With a slight abuse of notation, a few auxiliary definitions will help describe our procedure for calculating welfare gains. Based on $\mu$, define $\Phi(\tilde{z}, a \mid \mu, Z)$ as the conditional density of idiosyncratic shocks (in economy A) and asset holdings given aggregate shock $Z$ and the cross-sectional measure $\mu$. Also, let $P(\mu \mid Z)$ be the probability density of $\mu$ given $Z$ and let $F(\cdot)$ be the density function for aggregate shocks $Z$. The welfare gain for age-cohort $h$ can now be expressed as the number $\psi_{h}$ which results in average utility being equated:

$$
\iint\left[\int_{\tilde{Z} \times \mathcal{A}}\left\{V_{h}^{A}\left(\cdot, Z, \mu ; \psi_{h}\right)-V_{h}^{B}(\cdot, Z, \mu)\right\} \Phi(\tilde{z}, a \mid \mu, Z) d \tilde{z} d a\right] P(\mu \mid Z) d \mu F(Z) d Z=0
$$

where $V_{h}^{A}\left(\cdot, Z, \mu ; \psi_{h}\right)$ solves

$$
V_{h}^{A}\left(\cdot, Z, \mu ; \psi_{h}\right)=\max _{a_{h+1}^{\prime}}\left\{u\left(c\left[1+\psi_{h}\right]\right)+\beta \frac{\phi_{h+1}}{\phi_{h}} E V_{h+1}^{A}\left(\cdot, Z, \mu ; \psi_{h}\right)\right\},
$$

subject to the budget constraint (7), and the proportional change $\psi_{h}$ in consumption being held equal across all agents of age $h$. Our overall measure for welfare, denoted $\psi$ is just the weighted sum of $\psi_{h}$ weighted by $\varphi_{h}$ the cohorts size of those who are alive.

Our benchmark economy varies over time. Any comparison to an alternative economy, therefore, involves integrating over the welfare gains starting from alternative states in the benchmark economy. This is reflected in the integration over $\mu$ and $Z$ in equation (9). Our analysis takes explicit account of the equilibrium transition path to any of the alternative economies under considerations. Therefore, when we report average welfare gains they actually pertain to a weighted average of the welfare gains during the transitions for the different cohorts. The welfare gains reported for the new-born reflect the gain that would be associated without considering the transition.

\subsection{The Cost Of Business Cycles}

Overall, we find large welfare gains from removing aggregate productivity shocks and business cycle variation in idiosyncratic shocks. The welfare gains, reported in Exhibit 2, are $2.49 \%$ for the 'average' agent and $7.37 \%$ for new-borns. 
Understanding the economics behind our results involves understanding the interaction of several competing forces. The primary candidates are (i) aggregate productivity shocks, (ii) cyclical variation in the variance of idiosyncratic shocks (iii) 'general equilibrium effects:' the impact of aggregate savings on market clearing prices, and (iv) the role of finite lives. In order to decompose our overall results into components attributable to each of these effects, we conduct a number of additional experiments, each involving an economy in which progressively fewer of the effects are at work. In simple terms, we first eliminate aggregate productivity shocks $Z$, then business cycle variation in the variance of idiosyncratic shocks, and then general equilibrium effects. The differences we find each step of the way constitute the contribution associated with the factor most recently removed. We conduct these successive experiments for our OLG economy as well as for an otherwise identical infinitely lived agent economy. Differences across the infinitely lived agent economy and the OLG economy shed light on the role played by finite lives.

Exhibit 2 summarizes our experiments, and the corresponding welfare gains associated with each successive step:

\section{Exhibit 2: Summary of Experiments Underlying Welfare Decompo- sitions}

\begin{tabular}{|c|c|c|c|c|c|c|c|}
\hline $\begin{array}{l}\text { Notation for } \\
\text { Welfare Gain }\end{array}$ & \multicolumn{4}{|c|}{ Gain (\%) in OLG Economy } & $\begin{array}{l}\text { Gain }(\%) \text { in } \infty \\
\text { Lived Economy }\end{array}$ & $\begin{array}{c}\text { Eliminated } \\
\text { Effects }\end{array}$ & Comments \\
\hline & ${ }^{\gamma}{ }^{\gamma}$ & $\begin{array}{l}=2 \\
\text { T. Born }\end{array}$ & Avg. & $\begin{array}{l}=4 \\
\text { Born }\end{array}$ & $\gamma=2$ & & \\
\hline$\psi_{A, B}$ & 0.34 & 0.66 & 1.44 & 2.43 & 0.44 & $Z_{t}=E(Z) \forall t$ & Comparison includes transition \\
\hline$\psi_{B, C}$ & 0.24 & 0.90 & 1.03 & 5.09 & 0.22 & $\sigma_{H}=\sigma_{L}=\bar{\sigma}$ & Comparison with prices of economy B \\
\hline$\psi_{B, D}-\psi_{B, C}$ & 0.01 & -0.06 & 0.02 & -0.15 & -0.12 & $\sigma_{H}=\sigma_{L}=\bar{\sigma}$ & General Equilibrium effects \\
\hline$\psi$ & 0.59 & 1.50 & 2.49 & 7.37 & 0.54 & - & $\begin{array}{l}\text { Total Welfare Gain } \\
\psi=\psi_{A, B}+\psi_{B, D}\end{array}$ \\
\hline
\end{tabular}

Consider first the welfare gain of moving from our benchmark economy (denoted economy $A$ ) to an economy in which there are no aggregate productivity shocks nor are there any cyclical variation in idiosyncratic shocks (denoted economy $D$ ). For each column in Exhibit 2, $\psi$ represents the overall welfare gain we wish to decompose. The mechanics are as follows. The first row, $\psi_{A, B}$, represents the welfare gain of moving from the benchmark economy $A$ to an economy in which aggregate productivity 
shocks, $Z$, have been removed (denoted economy $B$ ). In this economy the aggregate productivity shock is set to its unconditional mean. Nonetheless, in the background we maintain the heteroskedasticity of idiosyncratic shocks. Hence, $\psi_{A, B}$ provides information on the direct effect of eliminating aggregate productivity shocks without the compounding effect of altering the cyclical structure of idiosyncratic shocks. In a similar fashion, $\psi_{B, C}$ denotes the welfare gain of moving from economy $B$ to an alternative economy $C$ - one without variation in the variance of idiosyncratic shocks. That is we set the variance of the idiosyncratic shocks to the unconditional level. In this alternative economy we also maintain the prices agents face in economy $B$. The idea is straightforward. Eliminating business cycle variations in idiosyncratic shocks will cause a reduction in precautionary savings which in turn will affect market clearing prices. $\psi_{B, C}$ provides a measure without any such compounding effects. Finally, $\psi_{B, D}-\psi_{B, C}$ is essentially a residual effect, describing the general equilibrium effects of savings on prices.

The results in Exhibit 2 indicate that removing only aggregate productivity shocks leads to substantial welfare gains (i.e., the row $\psi_{A, B}$ ). These welfare gains are larger then what Lucas (1987) found by an order of magnitude. These large gains reflect an interaction between aggregate fluctuations and the cyclicality in idiosyncratic risk. To better understand this point it is instructive to view an analytical expression for these welfare gains in a simple autarkic environment. Imagine an economy where aggregate consumption is i.i.d and can either be $(1+Z)$ in a boom or $(1-Z)$ in a recession. Conditional on these aggregate regimes, the variance of idiosyncratic shocks to logconsumption is $2 \sigma^{2} /(\lambda+1)$ and $\lambda 2 \sigma^{2} /(\lambda+1)$ respectively (where $\lambda>1$ ). It is shown in Appendix A that the welfare gain of removing aggregate productivity shocks in this case is

$$
\psi_{A, B}=\left[\frac{(1-Z)^{1-\gamma} \exp \left(\frac{\gamma}{2}(1-\gamma) \lambda \sigma^{2}\right)+(1+Z)^{1-\gamma} \exp \left(\frac{\gamma}{2}(1-\gamma) \sigma^{2}\right)}{\exp \left(\frac{\gamma}{2}(1-\gamma) \sigma^{2}\right)+\exp \left(\frac{\gamma}{2}(1-\gamma) \sigma^{2}\right)}\right]^{\frac{1}{\gamma-1}}-1
$$

The numerator is the expected utility in the economy with aggregate productivity shocks and cyclical variation in idiosyncratic shocks. The denominator is the expected utility in an economy with only business cycle variation in idiosyncratic risk. As the formula suggests, when $\gamma>1$ the regime in which the variance of idiosyncratic shocks is large (i.e., recession) gets a larger weight in computing expected utility. Thus the variation in aggregate productivity enhances the expected disutility associated with the increased idiosyncratic risk in downturns. It is important to note that the dependency between aggregate productivity and idiosyncratic risk is essential for this result. If idiosyncratic risk does not vary over the business cycle (i.e., $\lambda=1$ ) the resulting welfare gain is the same as when there is no idiosyncratic risk and effectively reduces to Lucas's welfare measure. Moreover, note that this welfare measure rises exponentially with risk aversion, a feature that is consistent with our numerical results when comparing the $\gamma=2$ and $\gamma=4$ case. 
The welfare gains of reducing business-cycle variation in the variance of idiosyncratic shocks (i.e., row $\psi_{B, C}$ ) are large. In our benchmark economy they amount to $1.03 \%$ for the average consumer and $5.09 \%$ for new-borns. Again, our simple autarkic example will serve as a useful benchmark. In this example we derive an analog of $\psi_{B, C}$, the welfare benefits of moving from an economy with heteroskadastic idiosyncratic shocks to an economy with homoskedastic shocks. To ensure that the comparison is meaningful we scale $\sigma^{2}$ by $\nu$ so that the mean and variance in the homoskadastic economy are the same as in the economy with heteroskedastic idiosyncratic shocks. The welfare gain in this case, for which a complete derivation is available in Appendix $\mathrm{A}$, is given by

$$
\psi_{B, C}=\left[\frac{1}{2} \exp \left(\frac{\gamma}{2}(\gamma-1) \sigma^{2}\left(\frac{2}{\lambda+1}-\nu\right)\right)+\frac{1}{2} \exp \left(\frac{\gamma}{2}(\gamma-1) \sigma^{2}\left(\frac{2 \lambda}{\lambda+1}-\nu\right)\right)\right]^{\frac{1}{\gamma-1}}-1
$$

Since by construction these two economies have equal unconditional means and variances, the difference in expected utility must come from higher moments in the distribution of idiosyncratic risk. In Appendix A we show that the welfare gains of removing counter-cyclical variation in consumption depend on the skewness and kurtosis of the processes. Both skewness and kurtosis are larger in the heteroskedastic economy than the homoskedastic economy. Agents dislike kurtosis but prefer positive skewness. This tradeoff between the skewness and kurtosis is captured by the terms $\left(\frac{2}{\lambda+1}-\nu\right)$ and $\left(\frac{2 \lambda}{\lambda+1}-\nu\right)$. For low risk aversion the skewness factor dominates and negative welfare gains arise. For slightly larger risk aversions $(\gamma>2)$ the kurtosis channel dominates which results in large positive gains. Again, these welfare gains rise non-linearly with risk aversion. Our computational results reflect this as well as the fact that welfare gains should be quite small with risk aversion equal to 2 .

In Appendix A we also provide some numerical values for the analytical analogs to $\psi_{A, B}$ and $\psi_{B, C}$ which are based on our estimated values for idiosyncratic earnings. Beyond providing additional intuition this also sheds light on how much of the welfare gains we have found are attributable to our models' specific income process. The welfare measures we report in the appendix are consistent for the most part with our computational numbers. Differences arise because consumption in our numerical model is neither i.i.d nor exogenous and various agents are borrowing constrained. Overall, the analytical analysis points to the fact that risk aversion is quantitatively important in our analysis but that the endogeneity of consumption can yield larger welfare gains than the fictious experiments based on exogenous consumption.

Finally, the general equilibrium effects, $\psi_{B, D}-\psi_{B, C}$, turn out to be negative and quite small on average. In general, these negative effects are larger for the young. The reason is due to the reduction in precautionary savings in the economy without fluctuations, where aggregate capital is smaller, wages are lower, and the return on capital is higher. Since the young have a lot of human capital but very little financial wealth these price effects work against them. 
In summary, our results thus far suggest that eliminating business cycle shocks is quantitatively important for agents' welfare. The key to these results is the interaction between aggregate productivity shocks and the stochastic properties of the cyclical variation in idiosyncratic shocks.

\subsubsection{Welfare Gains over the Life Cycle}

Figure 2 decomposes the welfare gains in Exhibit 2 by age. The dashed line decomposes the gains of removing aggregate productivity shocks (corresponding to $\psi_{A, B}$ ). The solid line provides the age profile of welfare gains of removing also the cyclical variation in idiosyncratic risk, but without accounting for the general equilibrium effects (prices are those of the economy with cyclical variation in idiosyncratic risk but without aggregate productivity shocks). Thus, the latter line corresponds to $\psi_{B, C}$. Finally, the solid-starred line in Figure 2 presents $\psi_{B, D}$, the age profile of welfare gains stemming from removing business-cycle variation in idiosyncratic risk in an economy without fluctuations in aggregate productivity, but where the general equilibrium effects of changing prices during the transition are incorporated.

It is clear that for each experiment the welfare gains are substantially larger for those who have many years left to live. The graph also shows that the large welfare gains attributable to eliminating aggregate productivity shocks decline monotonically with age. The welfare gains of eliminating business cycle variation in idiosyncratic risk are very large for the young and approach zero by retirement. The intuition for this is simple. The young hold most of their wealth in terms of human capital and are susceptible to large shocks relative to their wealth. The old on the other hand have zero human capital risk and have accumulated financial wealth with which they can effectively buffer shocks. The fluctuation in the old's wealth is solely due to fluctuation in the risky return on capital which is relatively small. Hence moving to the alternative economy is not a big attraction for them.

The difference between the solid line and the solid-starred line in Figure 2 represents the age profile of the general equilibrium effects $\left(\psi_{B, D}-\psi_{B, C}\right)$, and reveals that these effects are quite different for different age groups. In particular, the general equilibrium effects are negative for the young and are positive for the old. The explanation for these age-specific effects lies, again, in the respective composition of agent's wealth and the direction in which average prices have changed. In the economy with homoskedastic conditional variance agents save less and the resulting equilibrium is one with a higher average return on capital and lower wages. These changes in prices affect the old and the young differently. The old who hold large financial wealth gain from the rise in the return on capital, while the young lose, on average, due to the decline in wages.

In order to assess the importance of finite lives for the welfare calculations we report, we also analyze an economy which has infinitely lived agents but otherwise is 
similar to the OLG economy with risk aversion equal to 2. The difference between the welfare gains from the infinitely lived agent economy and the corresponding gains from the finitely lived agent economy can be attributed to the role of finite lives. In particular, to make the comparison across economies meaningful, we calibrate the infinite-lived agent economy so that the cross-sectional dispersion is the same as the cross-sectional dispersion in the OLG economy. ${ }^{3}$ The average welfare gain under the infinitely lived economy is $0.05 \%$ smaller than the corresponding number in the OLG economy. More generally, differences across welfare experiments are relatively small. At first blush this result may appear to contradict our intuition that the gains from eliminating business cycles ought to be larger for finitely lived agents. However, because in the OLG economy retirees do not work and, therefore, are not subject to idiosyncratic risk and because they constitute a sizable cohort, the welfare gains are downward biased. If one, more appropriately, compares the welfare gains in the infinitely-lived agent economy to the average welfare gains for those who work in the OLG economy larger differences arise.

\section{Conclusions}

Our main finding is that agents value the elimination of business cycles by a significant amount. The primary forces driving these welfare gains are (i) the direct elimination of aggregate productivity shocks and the way in which these shocks interact with variation in the variance of idiosyncratic shocks, and (ii) the elimination of cyclical fluctuations in the distribution of idiosyncratic risk. Both of these channels are different than alternative explanations put forth in the literature. In the first case, the dependency of the variance of idiosyncratic shocks on aggregate productivity shocks enhances the costs associated with the latter. The heteroskedastic nature of idiosyncratic shocks has a direct effect. Due to standard motives of consumption smoothing, agents prefer the homoskedastic economy since there is a smaller chance for extreme bad events that occur in downturns.

A drawback of our analysis lies in the exogenous way we introduce idiosyncratic risk over the business cycle. The issue of whether business cycle variation in the distribution of idiosyncratic risk will be eliminated once aggregate shocks are removed can not be answered structurally within our context. In our analysis we measure the gains were such variations to be eliminated. At a minimum, the large welfare gains we find suggest that elaborating on this issue is an important future research agenda. Along these lines, Beaudry and Pages (1999) and Gomes, Greenwood, and Rebelo (1999) explicitly model and analyze unemployment. Beaudry and Pages (1999) find significant welfare gains although smaller than what we have found. Reconciling our earnings process within such a framework and asking policy questions seems a natural avenue for further study.

\footnotetext{
${ }^{3}$ This amounts to reducing the conditional variances in recessions and booms by $15 \%$.
} 


\section{References}

Abowd, J. and D. Card, (1989), On the covariance structure of earnings and hours changes, Econometrica 57, 411-455.

Alvarez, F. and U. Jermann, (1999), Using asset prices to measure the cost of business cycles, Unpublished working paper, University of Chicago.

Atkeson, A. and C. Phelan, (1994), Reconsidering the costs of business cycles with incomplete markets, in Stanley Fischer and Julio Rotemberg eds., NBER Macroeconomics Annual 1994.

Beaudry, P. and C. Pages, (1999), The cost of business cycles and the stabilization value of unemployment insurance, manuscript, University of British Columbia.

Brav, A., G. M. Constantinides, and C. Geczy, (2000), Asset pricing with heterogeneous consumers and limited participation: Empirical evidence, Working paper, The Wharton School, University of Pennsylvania.

Castañeda, A., J. Díaz-Giménez, and J. V. Ríos-Rull, (1998), Exploring the income distribution business cycle dynamics, Journal of Monetary Economics 42, 93130 .

Cooley, T. F. and E. C. Prescott, (1995), Economic growth and business cycles, In Frontiers of Business Cycle Research, edited by Thomas F. Cooley. Princeton University Press: New Jersey.

Deaton, A. and C. Paxson, (1994), Intertepmoral choice and inequality, Journal of Political Economy 102, 437-467.

den Haan, W., (1994), Heterogeneity, aggregate uncertainty and the short term interest rate: a case study of two solution techniques, Working paper, University of California at San Diego.

Gomes, J., J. Greenwood, and S. Rebelo, (1999), Equilibrium unemployment, Manuscript, University of Rochester.

Heaton, J. and D. J. Lucas, (1996), Evaluating the effects of incomplete markets on risk sharing and asset pricing, Journal of Political Economy 104, 443-487.

Hubbard, R. G., J. Skinner, and S. P. Zeldes, (1994), The importance of precautionary motives in explaining individual and aggregate savings, Carnegie Rochester Conferance Series on Public Policy 40, 59-126.

İmrohoroğlu, A., (1989), Cost of business cycles with indivisibilities, Journal of Political Economy 97, 1364-1383. 
Krusell, P. and A. A. Smith, (1998), Income and wealth heterogeneity in the macroeconomy, Journal of Political Economy 106, 867-896.

Krusell, P. and A. A. Smith, (1999), The welfare effects of eliminating business cycles, Review of Economic Dynamics 2, 245-272.

Lucas, R. E., (1987), Models of Business Cycles, Basil Blackwell.

MaCurdy, T. E., (1982), The use of time series processes to model the error structure of earnings in a longitudinal data analysis, Journal of Econometrics 18, 83-114.

Otrok, C., (1999), On measuring the welfare cost of business cycles, Manuscript, University of Virginia.

Ríos-Rull, J. V., (1994), On the quantitative importance of market completeness, Journal of Monetary Economics 34, 463-496.

Souleles, N., (1999), Household securities purchases, transactions costs, and hedging motives, Working paper, The Wharton School, University of Pennsylvania.

Storesletten, K., C. I. Telmer, and A. Yaron, (1999), Asset pricing with idiosyncratic risk and overlapping generations, GSIA working paper no. 1998-E226, Carnegie Mellon University.

Storesletten, K., C. I. Telmer, and A. Yaron, (2000), Consumption and risk sharing over the life cycle, Unpublished working paper, Carnegie Mellon University. 


\section{Appendix A Welfare Gains in Autarkic Economies}

In this appendix we provide intuition for some of the sources underlying the welfare gains from removing fluctuations in aggregate productivity and counter-cyclical variation (CCV) in idiosyncratic earnings. We follow Lucas (1987) calculations assuming an endowment economy, no risk sharing, and consumption equals to income. We show that the welfare gains are closely related to probabilities of facing extreme events and depend on the skewness and kurtosis of the distribution of idiosyncratic consumption. We also illustrate the dependency of these results on the process for fluctuations in aggregate productivity. It should be noted, however, that in spite of the fact that our analysis below is realistically calibrated to income process, the welfare gains we compute analytically do not provide a bound on the welfare gains that can arise in our model. This is due to the fact that the welfare gains are a relative statement about expected utilities when consumption is endogenous. Also, in the computational experiments in the main text there are people who are borrowing constrained, something we abstract from in this appendix.

\section{A.1 Higher Moments and Welfare Gains}

In order to provide some intuition for the role different moments in the distribution of consumption have on welfare gains we start by abstracting from fluctuations in aggregate productivity. Let $f(c)$ and $g(c)$ be the probability density function for consumption under the heteroskedastic and homoskedastic economies respectively. For our analysis to be meaningful we impose the following conditions across the two economies,

$$
\begin{aligned}
\bar{c} & \equiv E_{f}(c)=E_{g}(c) \\
\operatorname{Var}_{f}(c) & =\operatorname{Var}_{g}(c)
\end{aligned}
$$

where the subscript in the mean and variance denotes the distribution (p.d.f) with which expectations are taken. These two restrictions imply that the unconditional mean and variance of the level of consumption are equal across the two economies.

The welfare gains to removing CCV are based on comparing the expected utilities across the two economies. The expected utility under the two economies can be approximated by a Taylor expansion around $\bar{c}$ as follows,

$$
\begin{aligned}
E_{i}(u(c)) \approx & u(\bar{c})+u^{\prime}(\bar{c}) E(c-\bar{c})+\frac{1}{2} u^{\prime \prime}(\bar{c}) E_{i}(c-\bar{c})^{2}+ \\
& \frac{1}{6} u^{\prime \prime \prime}(\bar{c}) E_{i}(c-\bar{c})^{3}+\frac{1}{24} u^{\prime \prime \prime \prime}(\bar{c}) E_{i}(c-\bar{c})^{4} \quad i=f, g
\end{aligned}
$$


where $E_{i}$ denotes again expectations with respect to the p.d.f's $f$ and $g$. Using our assumptions above and noting that the terms multiplying $u^{\prime \prime \prime}$ and $u^{\prime \prime \prime \prime}$ are simply the population skewness and kurtosis respectively, it follows that the difference in welfare across the two economies depends on

$$
E_{g}(c)-E_{f}(c) \approx \frac{1}{6} u^{\prime \prime \prime}\left(\text { Skewness }_{g}-\text { Skewness }_{f}\right)+\frac{1}{24}\left(\text { Kurtosis }_{g}-\text { Kurtosis }_{f}\right)
$$

In the case of CRRA utility function $u^{\prime \prime \prime}=-\gamma(-\gamma-1) c^{-\gamma-2}$ while $u^{\prime \prime \prime \prime}=-\gamma(-\gamma-$ $1)(-\gamma-2) c^{-\gamma-3}$. The first term is positive while the second term is negative for all $\gamma>0$. Since $\left(\right.$ Skewness $_{g}-$ Skewness $\left._{f}\right)<0$ and $\left(\right.$ Kurtosis $_{g}-$ Kurtosis $\left._{f}\right)<0$ there are two potential offsetting forces - the excess kurtosis in the heteroskedastic economy being an undesired feature, while the positive skewness contributing positively. As we show below it turns out that the differences in skewness are relatively small, and for $\gamma>2$ the kurtosis term dominates - which imply positive welfare gains. In summary, the analysis above should make it evident that once the mean and variance are equated across the two economies the remaining sources for welfare gains must show up through differences in higher moments.

\section{A.2 Welfare Gains Computed Analytically}

We continue to abstract from fluctuations in aggregate productivity and start our analysis with the heteroskedstic economy (i.e. the economy with time varying variance of income). As in the previous section, we assume for simplicity that agents are infinitely lived and have CRRA utility function. Let $\sigma^{2}$ denote the unconditional variance of log-consumption and let the cross sectional variance of log-consumption be $\lambda$ times larger in a recession than it is in a boom - both events can occur with probability of $1 / 2$ and are i.i.d across time. It is trivial then to show that the distribution of consumption follows,

$$
\log (c) \sim\left\{\begin{array}{lc}
N\left(-\frac{1}{\lambda+1} \sigma^{2}, \frac{2}{\lambda+1} \sigma^{2}\right) & \text { in a boom } \\
N\left(-\frac{\lambda}{\lambda+1} \sigma^{2}, \frac{2 \lambda}{\lambda+1} \sigma^{2}\right) & \text { in a recession }
\end{array}\right\}
$$

where the means for log-consumption are varying across recessions and booms so that the process satisfies $E(c)=E(c \mid$ recession $)=E(c \mid$ boom $)=1$. The unconditional variance of the level of consumption then follows,

$$
\operatorname{Var}(c)=\frac{1}{2}\left[\exp \left(\frac{2}{\lambda+1} \sigma^{2}\right)-1\right]+\frac{1}{2}\left[\exp \left(\frac{2 \lambda}{\lambda+1} \sigma^{2}\right)-1\right]
$$

We now proceed to specify the consumption process in the homeskedastic economy. As in the previous section for our welfare comparisons to be meaningful we must 
ensure that the unconditional mean and variance in the homoskedastic economy are equal to their respective quantities in the heteroskedastic economy. We therefore specify the following process for consumption in the homoskedastic economy,

$$
\log (c) \sim N\left(-\frac{\nu \sigma^{2}}{2}, \nu \sigma^{2}\right)
$$

where $\nu>1$ is a parameter that will scale the unconditional variance of log-consumption in the heteroskedastic economy to match the variances in levels across the two economies. That is $\nu$ is the solution to

$$
\exp \left(\frac{2}{\lambda+1} \sigma^{2}\right)+\exp \left(\frac{2 \lambda}{\lambda+1} \sigma^{2}\right)=2 \exp \left(\nu \sigma^{2}\right) .
$$

In order to derive the welfare gains of removing counter cyclical variation we need to calculate the expected utility under the two postulated consumption processes. The expected utility in the homoskedastic case is given by

$$
\begin{aligned}
E\{u(c)\} & =\frac{1}{1-\gamma} E \exp ((1-\gamma) \log (c)) \\
& =\frac{1}{1-\gamma} \exp \left(-\frac{\nu \sigma^{2}}{2}(1-\gamma)+(1-\gamma)^{2} \frac{\nu \sigma^{2}}{2}\right) \\
& =\frac{1}{1-\gamma} \exp \left(\frac{\gamma}{2}(\gamma-1) \nu \sigma^{2}\right)
\end{aligned}
$$

since $E\{(1-\gamma) \log (c)\}=-\frac{\nu \sigma^{2}}{2}(1-\gamma)$ and $\operatorname{var}((1-\gamma) \log (c))=\nu \sigma^{2}(1-\gamma)^{2}$.

The expected utility in the heteroskedastic case is then given by

$$
\begin{aligned}
E\{u(c)\} & =\frac{1}{2} E\{u(c) \mid \text { boom }\}+\frac{1}{2} E\{u(c) \mid \text { recession }\} \\
& =\frac{1 / 2}{1-\gamma}\left(\exp \left(\frac{\gamma}{2}(\gamma-1) \frac{2}{\lambda+1} \sigma^{2}\right)+\exp \left(\frac{\gamma}{2}(\gamma-1) \frac{2 \lambda}{\lambda+1} \sigma^{2}\right)\right)
\end{aligned}
$$

Let the welfare gain of moving from an economy with heteroskedastic process for consumption to a homoskedastic one be defined as the multiplicative increase in consumption, $1+\psi_{B, C}$, required to make an agent be equally well off under the two processes. Thus, $\psi_{B, C}$ is implicitly defined by

$$
\begin{aligned}
E\left\{u\left(c\left(1+\psi_{b, c}\right)\right) \mid \text { heteroskedastic }\right\}= & E\{u(c) \mid \text { homoskedastic }\} \\
& \text { so that } \\
\psi_{B, C}= & \left(\frac{E\{u(c) \mid \text { heteroskedastic }\}}{E\{u(c) \mid \text { homoskedastic }\}}\right)^{\frac{1}{\gamma-1}}-1 .
\end{aligned}
$$


Using equations (16) and (17), the welfare gain is computed as,

$$
\begin{aligned}
\psi_{B, C} & =\left[\frac{\frac{1 / 2}{1-\gamma}\left(\exp \left(\frac{\gamma}{2}(\gamma-1) \frac{2}{\lambda+1} \sigma^{2}\right)+\exp \left(\frac{\gamma}{2}(\gamma-1) \frac{2 \lambda}{\lambda+1} \sigma^{2}\right)\right)}{\frac{1}{1-\gamma} \exp \left(\frac{\gamma}{2}(\gamma-1) \nu \sigma^{2}\right)}\right]^{\frac{1}{\gamma-1}}-1 \\
& =\left[\frac{1}{2} \exp \left(\frac{\gamma}{2}(\gamma-1) \sigma^{2}\left(\frac{\lambda}{\lambda+1}-\nu\right)\right)+\frac{1}{2} \exp \left(\frac{\gamma}{2}(\gamma-1) \sigma^{2}\left(\frac{2 \lambda}{\lambda+1}-\nu\right)\right)\right]^{\frac{1}{\gamma-1}}-1
\end{aligned}
$$

Following our estimates in Exhibit 1 we set $\lambda=4$.8. The welfare gains for different risk aversions, given different values for $\sigma^{2}$ (and therefore different values for $\nu$ solving (15)) are:

\section{Exhibit A.2.1}

Welfare Gains of Removing Counter Cyclical Variation

\begin{tabular}{lcccccc}
\hline \multicolumn{7}{c}{ Welfare Gains $\left(\psi_{B, C}\right)$} \\
\hline$\sigma^{2}$ & .1 & .2 & .3 & .4 & .5 & .621 \\
\hline \hline & 1.022 & 1.043 & 1.063 & 1.085 & 1.1055 & 1.1315 \\
$\gamma$ & & & & \\
$\gamma=1.5$ & $-.11 \%$ & $-.41 \%$ & $-.89 \%$ & $-1.57 \%$ & $-2.42 \%$ & $-3.75 \%$ \\
$\gamma=2.0$ & $0 \%$ & $0 \%$ & $0 \%$ & $0 \%$ & $0 \%$ & $0 \%$ \\
$\gamma=2.5$ & $0.92 \%$ & $0.22 \%$ & $2.06 \%$ & $3.56 \%$ & $5.42 \%$ & $8.17 \%$ \\
$\gamma=3.0$ & $0.63 \%$ & $2.51 \%$ & $5.51 \%$ & $9.40 \%$ & $14.01 \%$ & $20.68 \%$ \\
$\gamma=4.0$ & $2.09 \%$ & $7.96 \%$ & $16.69 \%$ & $27.72 \%$ & $38.41 \%$ & $52.48 \%$ \\
$\gamma=5.0$ & $4.57 \%$ & $16.22 \%$ & $31.75 \%$ & $48.91 \%$ & $67.22 \%$ & $89.61 \%$
\end{tabular}

where the highest value, $\sigma^{2}=.621$ follows from $.621=\sigma_{\eta}^{2} /\left(1-\rho^{2}\right)$ using the parameters we estimated in Exhibit 1. The Table show that around $\gamma=2$ the welfare gain is very small and initially increases non-linearly with $\gamma$ greater than 2 , after which the rise in welfare is dominated by the kurtosis and is pretty much linear in $\gamma$.

\section{A.3 Removing Fluctuations in Aggregate Productivity}

We now amend equation (12) to account for fluctuations in aggregate productivity (consumption),

$$
\log (c) \sim\left\{\begin{array}{l}
N\left(\log (1+Z)-\frac{1}{\lambda+1} \sigma^{2}, \frac{2}{\lambda+1} \sigma^{2}\right) \\
N\left(\log (1-Z)-\frac{\lambda}{\lambda+1} \sigma^{2}, \frac{2 \lambda}{\lambda+1} \sigma^{2}\right) \\
\text { in a recession }
\end{array}\right\}
$$

where the means for log-consumption are varying across recessions and booms so that the process satisfies $E(c \mid$ recession $)=1-Z$ and $E(c \mid$ boom $)=1+Z$. The expected 
utility in the heteroskedastic case is then given by

$$
\begin{aligned}
E\{u(c)\}= & \frac{1}{2} E\{u(c) \mid \text { boom }\}+\frac{1}{2} E\{u(c) \mid \text { recession }\} \\
= & \frac{1 / 2}{1-\gamma}\left((1+Z)^{1-\gamma} \exp \left(\frac{\gamma}{2}(\gamma-1) \frac{2}{\lambda+1} \sigma^{2}\right)+\right. \\
& \left.+(1-Z)^{1-\gamma} \exp \left(\frac{\gamma}{2}(\gamma-1) \frac{2 \lambda}{\lambda+1} \sigma^{2}\right)\right)
\end{aligned}
$$

Let the welfare gain of moving from an economy with uncertainty in $Z$ to one without any uncertainty in $Z$ (although both economies exhibit heteroskedastic process for idiosyncratic consumption) be defined as the multiplicative increase in consumption in the economy with $Z>0$ economy, $1+\psi_{A, B}$, required to make an agent be equally well off as when $Z=0$. Thus, $\psi_{A, B}$ is implicitly defined by

$$
E\left\{u\left(c\left(1+\psi_{a, b}\right)\right) \mid Z>0\right\}=E\{u(c) \mid Z=0\}
$$

Based on equation (19), the welfare gain is computed as,

$$
\psi_{A, B}=\left[\frac{\frac{\exp \left(\frac{\gamma}{2}(\gamma-1) \frac{2}{\lambda+1} \sigma^{2}\right)}{(1+Z)^{\gamma-1}}+\frac{\exp \left(\frac{\gamma}{2}(\gamma-1) \frac{2 \lambda}{\lambda+1} \sigma^{2}\right)}{(1-Z)^{\gamma-1}}}{\exp \left(\frac{\gamma}{2}(\gamma-1) \frac{2}{\lambda+1} \sigma^{2}\right)+\exp \left(\frac{\gamma}{2}(\gamma-1) \frac{2 \lambda}{\lambda+1} \sigma^{2}\right)}\right]^{\frac{1}{\gamma-1}}-1
$$

Using the same parameters as in exhibit A.1 and letting $Z=3.80 \%$, we get the following numerical results,

\section{Exhibit A.3.1}

Welfare Gains of Removing Fluctuations in Aggregate Productivity

\begin{tabular}{cccccc}
\hline \multicolumn{6}{c}{ Welfare Gains $\left(\psi_{A, B}\right)$ in \% } \\
\hline$\sigma^{2}$ & 0 & .1 & .2 & .3 & .621 \\
\hline \hline$\gamma \approx 1$ & .07 & .07 & .07 & .07 & .07 \\
$\gamma=2$ & .15 & .39 & .64 & .88 & 1.61 \\
$\gamma=3$ & .22 & .95 & 1.63 & 2.21 & 3.36 \\
$\gamma=4$ & .29 & 1.68 & 2.72 & 3.33 & 3.89 \\
$\gamma=5$ & .36 & 2.47 & 3.48 & 3.81 & 3.95
\end{tabular}

Finally, note that if the idiosyncratic process for consumption is homoskedastic that is $\lambda=1$, equation (20) simplifies to,

$$
\psi_{A, B}=\left[\frac{1}{2}(1+Z)^{1-\gamma}+\frac{1}{2}(1-Z)^{1-\gamma}\right]^{\frac{1}{\gamma-1}}-1,
$$


which is also equal to the welfare gain of removing aggregate fluctuations in an economy without any idiosyncratic risk (i.e., the column where $\sigma=0$ ) and reduces to Lucas's welfare measure.

In summary, the welfare gains of removing fluctuations in aggregate productivity are magnified by the presence of CCV. These welfare gains are rising non-linearly in $\gamma$. The interaction cyclicality in idiosyncratic risk is what's important for these welfare gains as having homoskedastic idiosyncratic risk does not change the standard measures for the benefits of removing aggregate fluctuations. 


\section{Table 1}

\section{Aggregate Moments: Baseline Economy}

\begin{tabular}{lccc}
\hline \multicolumn{3}{c}{ Panel A: Population } & Moments, Baseline Theoretical Economy \\
& Std Dev & Autocorrelation & Correlation with Output \\
& & & \\
\hline Output & 0.041 & 0.62 & 1.00 \\
Consumption & 0.038 & 0.91 & 0.87 \\
Investment & 0.067 & 0.64 & 0.93 \\
\hline
\end{tabular}

Panel B: Sample Moments, Detrended U.S. Economy, 1955-1997

Std Dev Autocorrelation Correlation with Output

\begin{tabular}{lccc} 
& Std Dev & Autocorrelation & Correlation with Output \\
& & & \\
\hline Output & 0.047 & 0.87 & 1.00 \\
Consumption & 0.044 & 0.91 & 0.96 \\
Investment & 0.111 & 0.59 & 0.81 \\
\hline
\end{tabular}

U.S. sample moments are based on annual NIPA data obtained from the Bureau of Economic Analysis, 1955-1997. Each series was detrended by using a linear trend for the $\log$ of each series. Theoretical moments are also based on logarithms and are computed as sample averages of a long simulated time series for an economy where $\gamma=4$. 


\section{Figure 1}

\section{Cross-Sectional Moments by Age and Time}
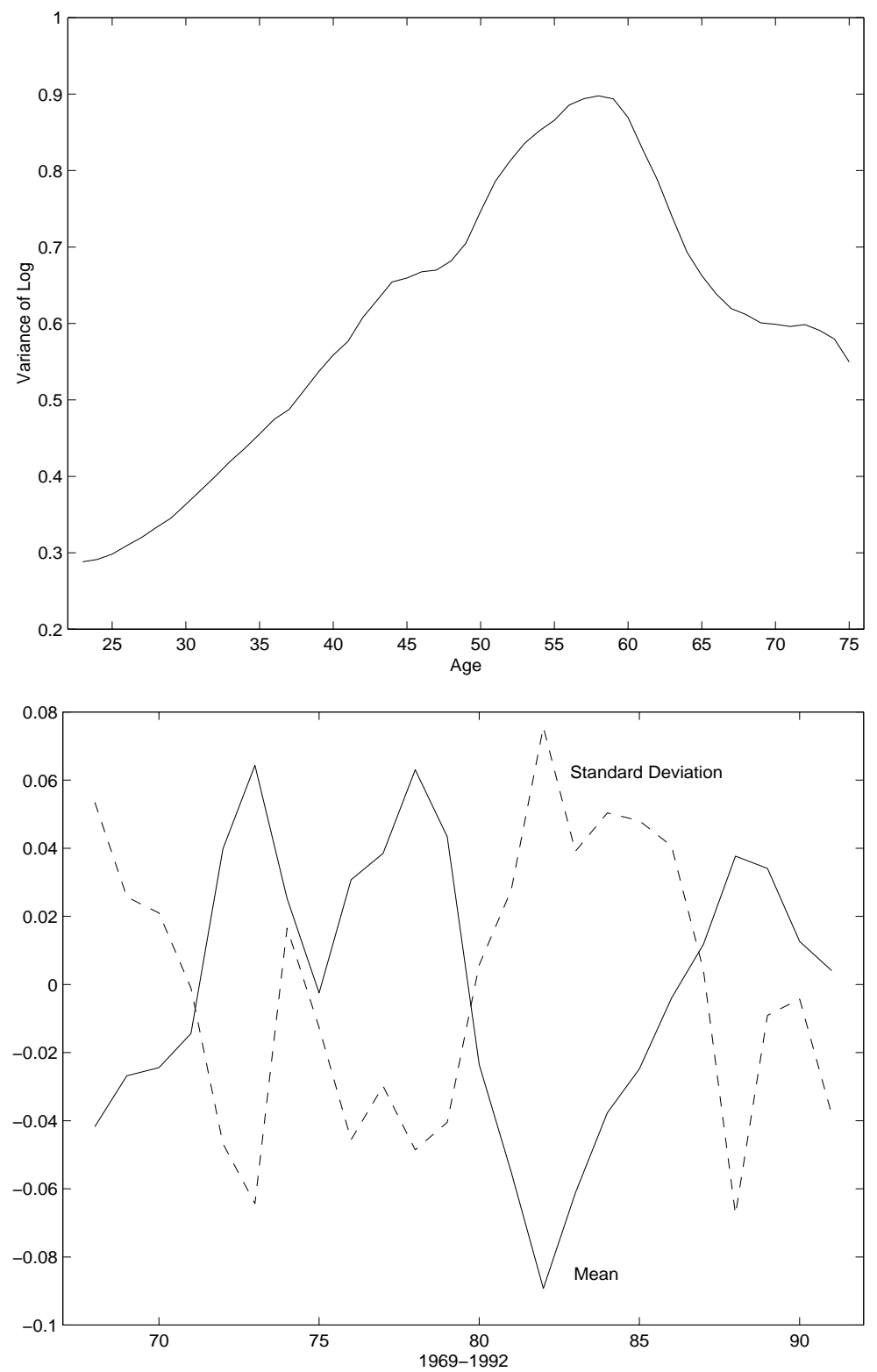

The top panel graphs the age profile of the cross-sectional variance of earnings, based on PSID data which has been pooled over the years 1969-1992. This graph controls for 'cohort effects' using the methods outlined in Deaton and Paxson (1994), and described in more detail in Storesletten, Telmer, and Yaron (2000). The bottom panel represents the (linearly detrended) cross-sectional mean and the cross-sectional standard deviation of PSID earnings, for the years 1969-1992. The standard deviation is additively scaled for graphical reasons. 


\section{Figure 2}

\section{Welfare Gains By Age}

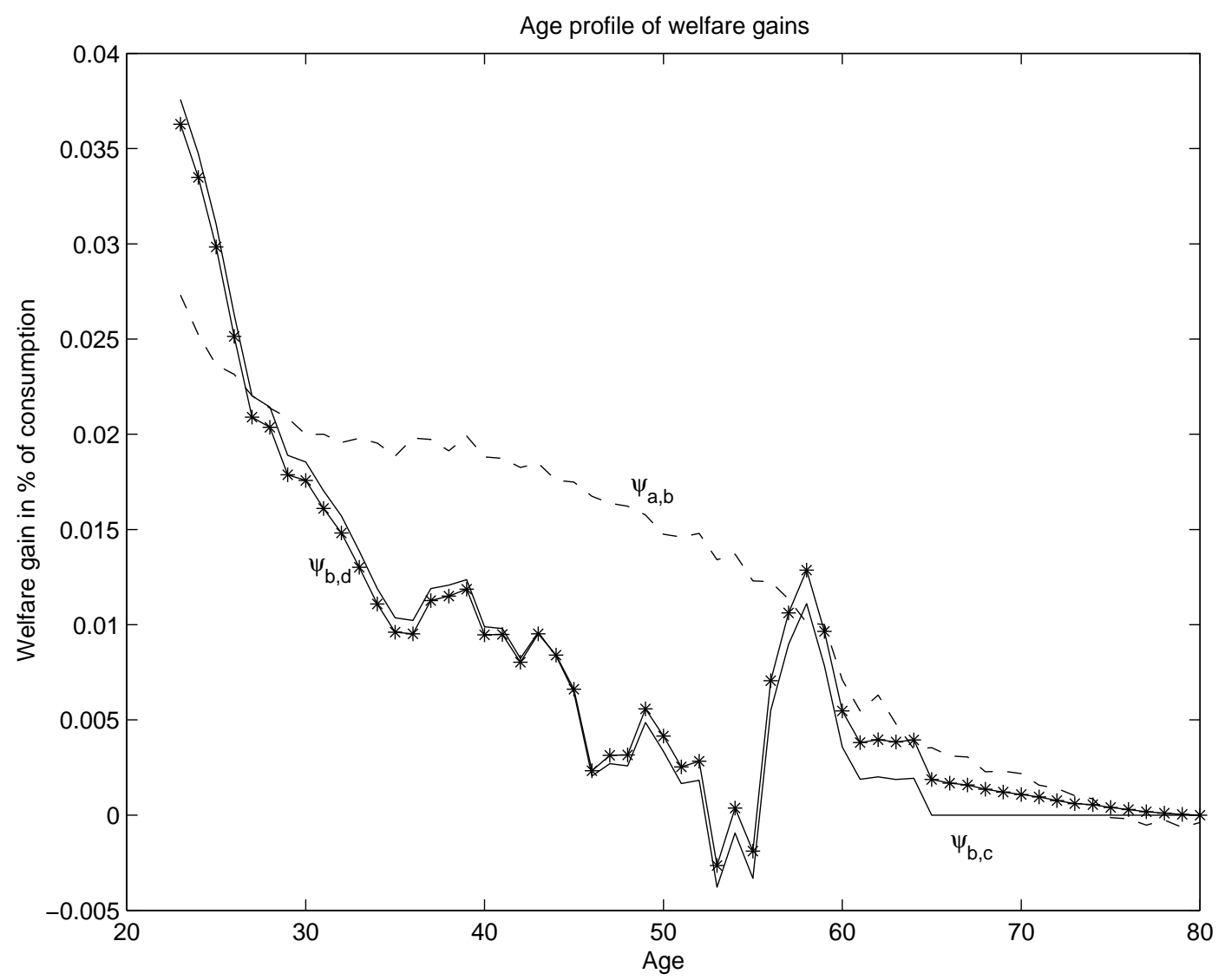

$\psi_{a, b}(h)$ depicts the age-profile of welfare gains of removing aggregate productivity shocks, while keeping the business cycle variation in individual risk.

$\psi_{b, c}(h)$ depicts the age-profile of welfare gains of removing business cycle variation in individual risk, but abstracting from general equilibrium effects of the transition.

Finally, $\psi_{b, d}(h)$ depicts the age-profile of welfare gains of removing business cycle variation in individual risk when general equilibrium effects of the transition have been accounted for. 